\title{
Ética, asesoría económica y política económica*
}

\author{
Stiglitz, J oseph E.*** \\ ** Profesor de Economía en Columbia University. Ejerció el cargo de Vice-presidente \\ Senior y Economista Jefe del Banco Mundial así como Presidente del Consejo \\ Estadounidense de Asesores Económicos durante el gobierno del Presidente Clinton. \\ Premio Nobel de economía 2001.
}

\section{Resumen}

En los últimos cincuenta años han ocurrido cambios cruciales que han involucrado a todos los países del mundo, mostrando que cuando hay crecimiento el desarrollo es posible, así como también, que es factible combinar crecimiento con la reducción de la pobreza; pero esa tarea no resulta ser nada fácil. En este ensayo se reflexiona sobre las dimensiones éticas de diversos aspectos vinculados al desarrollo y la economía internacional por considerar que la ausencia en el debate sobre políticas de reducción de la pobreza, de las dimensiones éticas y de valores como la honestidad y la justicia impiden el desarrollo del nuevo humanismo no como antítesis del razonamiento económico sino como su complemento.

Palabras clave: Ética, política económica, pobreza, justicia social, desarrollo.

\section{Ethics, Economic Advice and Economic Policy}

\begin{abstract}
Over the last fifty years, crucial changes have occurred which have involved every country in the world, and which indicate that when there is growth, development is possible, and also that it is possible to combine growth with the reduction of poverty, but that it is not an easy task. This essay reflects on the ethical dimensions of divers aspects related to development and the international economy since this absence of ethical dimensions and values such as honesty and justice in the debate on poverty reduction policy impedes the development of a new humanism, not as an antithesis to economic reasoning, but as a complement.
\end{abstract}

Key words: Ethics, economic policy, poverty, social justice, development. 
Recibido: 02-11-29. Aceptado: 02-12-09

\section{I ntroducción}

En esta ocasión, me gustaría referirme a las dimensiones éticas de diversos aspectos vinculados al desarrollo y a la economía internacional que he tenido que abordar durante los últimos ocho años. Hace ya mucho tiempo que los economistas han venido esgrimiendo la importancia del factor "interés propio" no solamente para explicar comportamientos, sino también para lograr resultados eficientes. Pero igualmente han estado conscientes de las limitaciones de estas perspectivas. Además de que el paradigma interés propio/mercado resulta con frecuencia inadecuado para generar eficiencia, aún cuando lo logra, los resultados obtenidos no necesariamente están en concordancia con las nociones de justicia social. Aún así, en el ámbito de la política económica, los gobiernos suelen justificar la ayuda externa y otras políticas dirigidas a los países más pobres en función de su propio interés: a saber, cómo incrementan dichas políticas el ingreso a escala global, y por ende aumentan las exportaciones de su propio país, o cómo contribuyen a la estabilidad política global, que resulta beneficiosa para todos. Este tipo de argumentos distraen la atención de la justificación moral de estas políticas.

La ética en el marco de la relación entre países de mayor y menor nivel de desarrollo impone que los países más desarrollados traten a los de menor desarrollo en forma equitativa, conscientes de la situación de desventaja en lo económico en que se encuentran los segundos, y con el reconocimiento de que el aprovecharse del propio poder económico inevitablemente lesionará a los pobres en los países en vía de desarrollo.

En diversas ocasiones hemos visto un marcado incumplimiento de este precepto en las relaciones económicas globales: una agenda de comercio internacional establecida con miras a promover los intereses de los países más desarrollados, por lo menos parcialmente, a expensas de los de menor desarrollo - a un grado tal que, en promedio, la región más pobre del mundo se encontró en una situación más precaria al finalizar la última ronda de negociaciones comerciales que antes de las mismas- al igual que un acuerdo internacional en materia ambiental en virtud del cual los mismos países ricos que producen actualmente el mayor nivel de contaminación tendrán en el futuro la posibilidad de continuar haci éndolo de la misma manera.

También otras dimensiones de la globalización ilustran este incumplimiento de los principios éticos básicos. Pensemos en el argumento a favor de la libre movilidad del capital, la que tiende a: incrementar la eficiencia a escala mundial. Haciendo caso omiso, 
claro está, de los efectos potencialmente devastadores para los países pequeños y pobres -y a los pobres dentro de los mismos- que no tienen la capacidad de resistir los embates de las variaciones aparentemente irracionales de las apreciaciones de los inversionistas y las consiguientes reversiones de los flujos de capital. La globalización de estos movimientos de factores se parece mucho a la globalización en el comercio: en ese ámbito presenciamos cómo los poderosos le piden a los países en desarrollo que abran sus mercados a los bienes provenientes de los países más industrializados, mientras mantienen cerrados los propios. El factor que exportan los países desarrollados es capital y el factor que abunda es mano de obra.

Desde una perspectiva económica, la libre movilización del recurso laboral es tan útil para lograr la eficiencia global como el libre movimiento del capital. Sin embargo, los países desarrollados no están abogando por un libre movimiento del sector laboral, no están ofreciendo abrir sus puertas a los pobres del mundo. La razón es evidente: están plenamente conscientes del trastorno social -y de la consiguiente presión política- que causaría una migración de esta naturaleza. Simplemente no logran ponerse en el lugar de los países en desarrollo. No son receptivos cuando dichos países plantean exactamente esas mismas objeciones a la apertura de sus fronteras a aquellos factores y bienes que abundan en el mundo desarrollado.

Mis señalamientos estarán referidos a la ética pragmática, es decir, que no trataré de derivar principios éticos a partir de consideraciones de orden superior. Prefiero explorar las implicaciones que tienen determinados preceptos éticos ampliamente aceptados en la conducción de las relaciones económicas internacionales. De la misma manera, evaluaré determinadas acciones, señalando cuáles pueden ser vistas como acciones fundadas en principios. No emprenderé la tarea mucho más ambiciosa de definir un conjunto de principios para la acción, si bien es de suponer que lo que estableceré será considerado como un preludio a dicha labor. Me valdré de esta oportunidad tanto para plantear interrogantes como para aportar respuestas $\underline{1}$.

Centraré mis comentarios en cinco conceptos específicos: honestidad, equidad, justicia social (que incluye la preocupación por los pobres), elementos externos y responsabilidad. Si bien el significado de la mayoría de estos términos debería resultar evidente, permítanme unos breves comentarios acerca de cada uno de ellos. La honestidad excede el concepto contrapuesto a la mentira frontal; se acerca más a la máxima de “decir la verdad, toda la verdad y solamente la verdad". Inducir impresiones erradas -afirmar que existen pruebas de alguna aseveración cuando no las hay- es una violación del principio de honestidad. Equidad incluye lo que los economistas Ilaman la equidad horizontal -ya 
sea dar el mismo tratamiento a todos (es decir no discriminar por motivos de raza o género) o bien, en la medida en que resulta deseable tratar de manera diferente a quienes se encuentran en circunstancias que también lo son (por ejemplo, los ancianos y los discapacitados pueden requerir un tratamiento especial), brindar el mismo trato a quienes se encuentran en posiciones similares.

Naturalmente, cabe preguntar cuáles son las diferencias significativas, que justifican ese tratamiento diferente. Por lo tanto, el favoritismo- incluso el que consiste en brindar trato especial a intereses especiales- es una violación de la norma ética de equidad. La justicia social incluye el ayudar a los necesitados, y hacerlo en forma tal que incremente su sentido de la dignidad así como su capacidad de asumir su propia responsabilidad individual. "Elementos externos" implica que las personas no deben imponer costos a terceros. Desde este punto de vista, botar basura "está mal", es violar una norma ética. La responsabilidad es la norma ética en virtud de la cual los individuos deben asumir la responsabilidad de sus acciones y las consecuencias de las mismas.

En todos los aspectos de la economía y de la elaboración de políticas en este ámbito se plantean consideraciones vinculadas a la ética. Reconocemos, por ejemplo, los problemas éticos planteados por conflictos de interés, y debido a la multitud de posiciones en que se encuentran las personas, resulta inevitable que se presenten dichos conflictos. En la actualidad, en virtud de las normas éticas modernas, es requisito dar a conocer los conflictos de interés significativos, como expresión del principio de honestidad 2 . Habitualmente, no se considera inmoral realizar acciones en calidad de fiduciario, 0 brindar asesoría hacia un propósito que pueda resultar también en beneficio propio; es sin embargo inmoral no divulgar el conflicto de interés, para que los potencialmente afectados puedan tomar las debidas precauciones. En el marco de la teoría moderna de las instituciones se reconoce que sus representantes, en general, no adoptan como propios los intereses de aquellas personas (directores) que supuestamente deben defender como si lo fueran; incumbe al dirigente la responsabilidad de diseñar estructuras de incentivos que permitan alinear dichos intereses en la medida de lo posible. Sin embargo, es incorrecto que el representante de la institución incurra en actos como, por ejemplo: robar, aceptar comisiones indebidas de clientes, o en diversas prácticas de corrupción.

Los asesores tienen que hacer frente a diversos elementos éticos, al igual que los burócratas y funcionarios gubernamentales electos, como los vinculados a la corrupción. Los gobiernos también deben abordar temas éticos en el diseño de los programas, y lo mismo ocurre con las instituciones internacionales. Inicio el presente ensayo sometiendo el papel del asesor económico al análisis ético: ¿Qué significa ser un asesor económico 
ético? Esta es una pregunta importante, porque las instituciones financieras internacionales están activamente dedicadas a la asesoría económica. Al hacerlo ¿se comportan de manera ética? Examinaré seguidamente una serie de temas específicos: la ética en el trato que dan los países desarrollados a los que se encuentran en desarrollo, es decir la ética en el área del comercio, de las políticas ambientales globales, de la eliminación de la deuda, en materia de estrategias de crecimiento, manejo de crisis, y por último, temas éticos en política demográfica.

\section{La ética del asesor económico}

En la mayoría de las profesiones existen claros principios éticos. En la medicina están contenidos en el Juramento Hipocrático, siendo uno de ellos el "no causar daño". En cierta forma, el propósito de estas normas éticas es el de mitigar las consecuencias adversas resultantes del intento descontrolado por satisfacer el interés propio, especialmente las que surgen cuando hay problemas vinculados a las instituciones (casos en los que, debido a una falta de información, una de las partes puede aprovecharse de la otra). La violación de dichos principios éticos lesiona a todo el gremio profesional (en este contexto, puede decirse que es un elemento externo). Destruye la confianza. Por ejemplo, no es ético que un médico prescriba una medicina determinada porque el fabricante le pagará una comisión por hacerlo. El paciente, al desconocer el motivo por el cual su médico elige una medicina en vez de otra, supone que la está prescribiendo en atención a su mayor conveniencia (la del paciente), no porque esté recibiendo algo a cambio. En este sentido, faltan a la ética las acciones que podrían presentar un conflicto de interés entre el profesional y la persona a quien está prestando un servicio. Habida cuenta de que la información es un aspecto central del servicio que brindan la mayoría de las profesiones, la honestidad es una virtud de importancia crítica.

Destruir la confianza conlleva un gran costo económico. En modelos simplistas, el interés propio individual conduce a resultados eficientes, puesto que las personas actúan, y es de esperarlo así, para favorecer sus intereses. Sin embargo las teorías modernas, en las cuales las imperfecciones de la información y los mercados incompletos juegan un papel importante, el comportamiento que atiende el interés propio no suele conducir a resultados eficientes. Los equilibrios basados en la confianza pueden conducir a mejores resultados que aquellos en los cuales está ausente. El paciente, por ejemplo, se sentirá impulsado a buscar una segunda y una tercera opinión, porque tendrá recelo de la actitud del médico y de la objetividad de su consejo si piensa que para el médico está en juego un interés financiero. Por lo tanto, hay un argumento de naturaleza instrumental a favor del comportamiento ético. 
Algunos de los principios que rigen la conducta de los asesores económicos son muy claros. Es evidente que existe un mandato ético en cuanto a no aprovecharse indebidamente de la información adquirida por el manejo confidencial de la misma en calidad de asesor, o de utilizar directamente los contactos generados por dicha condición con fines de lucro personal 3 . Más aún, existen normas éticas (y a menudo legales) relativas a la divulgación (de determinada información). La transparencia mitiga, aunque no elimina por completo, el peligro de una asesoría motivada por interés propio del asesor.

Un consultor de una empresa que tuviese una posición corta en las acciones de la misma tendría un incentivo para brindar una asesoría tendiente a la reducción de su valor de mercado. Son muy pocas las empresas que le permitirían a un consultor mantener una posición como ésta si estuviesen en conocimiento de ello. De la misma manera, un consultor contratado por una empresa para asesorarla en la elección de un proveedor no debería tener intereses financieros vinculados a ninguno de los proveedores, y en caso de que sea así, debe divulgar la información pertinente, ya que lo contrario sería no ético.

Sin embargo, hay también implicaciones menos directas, y son éstas las que quisiera señalar. En primer lugar, la honestidad exige la completa manifestación de las limitaciones del conocimiento. De hecho, esto se ha convertido en parte explícita de las normas de la buena ciencia. En las ciencias exactas, siempre se presenta el rango de estimación, los intervalos de confianza dentro de los cuales se ubican determinados resultados.

El reconocimiento de estas incertidumbres es aún más importante en las ciencias sociales. Las diferentes propuestas se adoptan con variados grados de confianza. Por ejemplo, los economistas pueden afirmar con bastante certeza que si los gastos de un gobierno exceden considerablemente sus ingresos durante un período de tiempo prolongado, es probable que enfrenten problemas, o que la hiperinflación tiene efectos adversos en la economía.

Podemos afirmar con bastante seguridad que la liberalización de los mercados de capital está asociada a mayores riesgos, especialmente para las economías pequeñas, abiertas y en desarrollo. Por otra parte, la honestidad haría que un asesor que recomiende liberalizar los mercados de capital también diga claramente que se carece de pruebas empíricas que confirmen que dicha liberalización conduce a un crecimiento más rápido, y que son controvertidas las teorías que abogan por esta política. Debería enriquecer cualquier debate al respecto diciendo que la liberalización de las cuentas de capital favorece la 
inversión extranjera directa, pero debe señalar igualmente que China, el país que ha tenido el mayor éxito en atraer dicha inversión, no ha adoptado esta liberalización.

Un segundo elemento que debe sincerarse en aras a la honestidad es el reconocimiento de la existencia de más de una política de eficiencia de Pareto. Hay aspectos más o menos ventajosos, en la medida en que las distintas políticas tienen diferentes efectos en los varios grupos, con niveles de riesgo desiguales en los diversos segmentos de la sociedad. La asesoría económica debería centrarse en asegurar la eficiencia de las políticas (en términos técnicos, para asegurar que la economía se encuentre en el límite Pareto), pero es responsabilidad de los procesos políticos seleccionar los puntos de dicho límite.

Cuando un economista recomienda un punto determinado, se está valiendo de su supuesto conocimiento económico para promover una posición política. Esto es dar una impresión errónea. Resulta especialmente seria la situación cuando es de suponer que dicho asesor, o intereses a los que está ligado, podrían beneficiarse en forma desproporcionada de las políticas específicas adoptadas. Por ejemplo, si hay una serie de políticas y algunas resultan más ventajosas para quienes están en el mercado financiero, sería falta de ética de un asesor que represente intereses financieros el no revelar el hecho de que la política específica que (él) favorece resultaría especialmente favorable para dichos grupos.

En la actualidad existe en la esfera pública un problema de "puertas giratorias". Las personas tienen lo que podría considerarse como intereses contingentes. Quienes favorecen intereses especiales mientras están activos en el ejercicio de cargos públicos son a menudo recompensados con cargos lucrativos después de cesar en dichas funciones. Muchos gobiernos están conscientes del conflicto de intereses creado por esta circunstancia, y con el fin de atenuar los aspectos éticos que surgen inevitablemente, insisten en que los funcionarios gubernamentales no deben aceptar ningún empleo vinculado con quienes podrían presentar dicho conflicto durante un determinado período de tiempo después de cesar en sus funciones públicas, o limitan la naturaleza de las actividades a las que se pueden dedicar. Indudablemente, sin normas de esta índole (e inclusive con ellas) sería falta de ética brindar una asesoría favorable a dichos intereses sin revelar tanto las consecuencias para dichos grupos, como lo que podría considerarse como el inter és contingente del asesor. Por supuesto que las empresas que contratan a estos "devotos" servidores públicos afirman que lo hacen no por recompensar servicios prestados en el pasado sino sobre la base de la capacidad demostrada en el ejercicio del cargo público. Resulta evidente que es prácticamente imposible establecer la línea divisoria entre ambas condiciones. 
En tercer lugar, la preocupación por la justicia social debería hacer que un asesor económico preste especial atención a las posibles consecuencias de las políticas para los pobres. La información incide en la acción, y si bien el economista tiene la responsabilidad moral de no imponer sus valores, también la tiene en el sentido de cerciorarse de que haya suficiente información disponible para permitir la adopción de decisiones de política morales, como por ejemplo las que reflejen los principios de la justicia social. 4 Cuando una política presenta riesgos para la economía, y es probable que los mismos afecten considerablemente a los pobres, el asesor debe señalarlo, especialmente si el peso de dichos riesgos es desproporcionado. Hay entonces la responsabilidad moral de adoptar enfoques creativos, en la medida de lo posible, acerca del tipo de políticas que podrían brindar más oportunidades a los pobres, permiti éndoles asumir la responsabilidad por su propio bienestar.

De la misma manera, existe el imperativo moral de preocuparse por las generaciones futuras, el economista debe prestar atención igualmente a las consecuencias ambientales, y debe brindar la información que permita formular mejores políticas ambientales $\underline{5}$. Estos son preceptos generales que son válidos para todos los asesores de política. He afirmado que una de las ventajas de la estructura institucional del Consejo de Asesores Económicos de los Estados Unidos consiste en que reduce el rango de potenciales conflictos de interés. Se designa a los miembros por un corto período, y luego regresan al mundo académico. Así, su incentivo es el de brindar información relativamente precisa, ya que sus consejos estarán bajo la escudriñadora mirada de sus pares académicos. Las normas de la profesión exigen establecer la mayoría de las distinciones a las que me he referido, inclusive la de diferenciar entre intereses especiales e intereses generales, entre los efectos de eficiencia y los de distribución. Además, conforme a las regulaciones del gobierno de Estados Unidos, deben renunciar a todos los intereses financieros, 0 colocarlos en fideicomisos sin denominación y en todo caso son pocos los que tienen cuantiosos intereses financieros (Stiglitz, 1997).

Una de las principales actividades de las instituciones financieras internacionales es la de asesorar. Al evaluar cómo lo hacen, siento que con excesiva frecuencia no cumplen a cabalidad los puntos descritos. Tratan de imponer un determinado conjunto de políticas, como condicionamientos para conceder préstamos, en vez de describir las opciones de políticas y sus respectivas ventajas y desventajas y de estimular a los países para que ellos mismos asuman la responsabilidad de elegir entre dichas opciones. No aclaran debidamente las incertidumbres asociadas a las políticas que promueven, y afirman una serie de enunciados acerca de la eficacia de las mismas que no pueden ser comprobados. 
Más importante aún, por lo menos en el pasado, además de haber omitido la debida preocupación por los posibles efectos adversos de las políticas para los pobres, ni siquiera mencionaron sus riesgos probables. Han insistido continuamente en la conveniencia de adoptar una serie de políticas "dolorosas", sin parecer preocuparse por quienes tendrían que soportar sus consecuencias. Muchas de sus políticas parecen beneficiar en forma desproporcionada los intereses financieros, aspecto que no señalan, así como tampoco hacen mención de lo que he considerado los intereses contingentes de sus funcionarios- lo cual se pone de manifiesto en el hecho de que muchos de los integrantes de su personal dejan el Fondo Monetario Internacional o el Banco Mundial para trabajar en instituciones financieras privadas 6 .

\section{Enfrentar dilemas morales como asesor económico}

Llego así al dilema moral que es, probablemente, el más difícil de los que debe enfrentar quien asesora en materia de políticas, a saber: ¿Qué debe hacer cuando se ve ante una política que considera, en determinado sentido, "inmoral"? Debe decirlo abiertamente, corriendo así el riesgo de perder influencia ¿Representa el silencio una forma de complicidad? No existen respuestas fáciles, pero unos cuantos ejemplos pueden contribuir a ilustrar la naturaleza del dilema.

Cuando los asesores económicos del Presidente Johnson trataron de pronosticar hacia dónde se dirigía la economía (y por ende qué tipo de políticas macro-económicas se requerirían para sostener una situación de pleno empleo sin inflación), se encontraron ante el siguiente problema: el gobierno estaba gastando en la guerra de Vietnam más de lo que estaba dispuesto a admitir. Una de las opciones para los asesores era actuar como si las cifras oficiales fuesen las correctas, y recomendar así una política fiscal claramente equivocada. O bien podían decidir no emplear dichas cifras, sino otras más ajustadas a la realidad, con lo cual estarían violando las "confidencias" del gobierno. Claro está que el respetar dichas confidencias resultaba también cuestionable en lo moral, ya que en las sociedades democráticas, podría afirmarse que existe un imperativo moral de apertura y transparencia; en última instancia, un funcionario público está "al servicio" de la gente, la cual tiene el derecho de saber lo que está haciendo el gobierno. Unos años después, el asesor económico del Presidente Reagan, Marty Feldstein, se encontró ante un problema similar, durante mucho tiempo había defendido la importancia de mantener un alto nivel de ahorro nacional; a pesar de ello, Reagan había insistido en un recorte tributario que originó enormes déficits, con el potencial riesgo de socavar la prosperidad futura del país.

Algunos economistas predijeron que, contradiciendo todo pronóstico, el recorte tributario 
generaría suficiente crecimiento, de manera que no habría déficit. La honestidad intelectual exigiría una discusión relativa a la falta de pruebas para llegar a esa conclusión, así como de los riesgos asociados a elevados niveles de déficit. En esta oportunidad, Feldstein expresó su opinión pública y firmemente señaló las potenciales consecuencias adversas de la política, pero al hacerlo debilitó la efectividad del Consejo de Asesores Económicos bajo la Administración Reagan.

En lo personal también me vi ante un dilema similar en mi calidad de Economista Jefe del Banco Mundial. Pensaba que las políticas adoptadas por el FMI después de la crisis financiera de los países del Sudeste Asiático conducirían a recesiones y depresiones más profundas y prolongadas de lo necesario. Creía igualmente que se estaban anteponiendo los intereses financieros de los acreedores extranjeros a las preocupaciones por los pobres y las pequeñas empresas. A mi entender, era casi seguro que las políticas impuestas por el FMI causarían estragos en sus vidas y medios de subsistencia. Intenté en forma discreta, en el marco de los procesos institucionales, cambiar las políticas, o por lo menos promover un debate abierto acerca de las mismas (basado en mi convicción de que los errores eran tan evidentes, que dicho debate conduciría rápidamente a un cambio de dirección). Sin embargo, debido a las profundas rigideces institucionales (y a los poderosos intereses especiales y sus ideologías), además de no poder revertir las políticas, ni siquiera logré generar una discusión abierta de las mismas. Me parecía que allí se perfilaba un problema moral básico ¿Cómo podía quedarme callado? Sentí una intensa obligación moral de pronunciarme. Por lo menos de señalar los riesgos de dichas políticas.

¿Qué puede decirse acerca de la actitud moral de quienes se esforzaron por sofocar la discusión pública? Afirmaron que la misma podría debilitar la confianza en las políticas, lo cual a su vez impediría obtener los efectos deseados. Por ello, en su criterio, hablar abiertamente era algo equivocado, porque sin confianza el capital seguiría saliendo del país, y con ello debilitaría la economía aún más, afectando a los pobres. De hecho, abogaban a favor no sólo de una falta de sinceridad y de transparencia sino de una cierta falta de honestidad: la aseveración de que las políticas tenían probabilidad de ser más efectivas de lo que la evidencia justificaba. Deberían resultar obvios los peligros de este tipo de actitud. En casi todos los ámbitos, cualquier gobierno podr ía afirmar que la falta de honestidad, las verdades a medias, son "medios" justificados por el fin. Posiblemente el Departamento del Tesoro o el FMI comparten este criterio. Pero también el Departamento de Defensa podría sostener lo mismo en relación a cada aspecto de sus actividades (desde la toxicidad del Agente Naranja hasta la verdadera magnitud de una amenaza enemiga).

Este tipo de posiciones, además de ser peligrosas y de socavar la democracia, resultan, 
en última instancia, auto- destructivas. Repetir aseveraciones de esta naturaleza debilita la credibilidad del gobierno. Resultan especialmente problemáticas en el ámbito económico, ya que, inevitablemente, se constatará con frecuencia lo equivocado de las predicciones, y las excusas posteriores a los hechos siempre lucen absurdas. $Y$, en efecto, la falta de credibilidad basada en los pronósticos excesivamente confiados, contribuye en sí misma a la falta de eficacia de las políticas del FMI. En última instancia, esta falta de credibilidad facilitó mi decisión: el que yo expresase abiertamente mis opiniones o no poco afectaría la confianza en la política, pero sí podría ejercer alguna influencia en cuanto a la política adoptada, con lo cual se podrían evitar, o en todo caso reducir, sus consecuencias en materia de recesión.

En general, no existe una respuesta fácil para estos dilemas morales ante los que se encuentran los asesores en materia de políticas. Cada situación es diferente. Un elemento crítico de evaluación es el de determinar cuáles acciones puede emprender con la mayor probabilidad de que conduzcan a lo que considera moralmente correcto. En algunos casos, la renuncia puede ser la respuesta más efectiva, pero aún cuando se contempla esta posibilidad, el momento en el tiempo es muy importante. Una renuncia oportuna puede lograr cambios más efectivamente que cualquier cantidad de argumentos. A menudo luce como una medida de alto costo, y como tal, el hecho de que un funcionario público - quien sin duda ha trabajado arduamente para lograr ocupar su posición destacada- esté dispuesto a adoptar una medida tan drástica, emite una señal efectiva en relación a su profunda convicción acerca del aspecto debatido.

\section{La ética y la política econ ómica internacional}

He afirmado que si bien cabe esperar que las personas actúen generalmente impulsadas por su propio interés, existen circunstancias en las cuales consideramos que dicha conducta no es ética. Lo mismo ocurre con los países. Tenemos la expectativa de que los países, por lo general, actuarán para beneficio de sus ciudadanos. Sin embargo, hay límites, y algunos comportamientos carecen de ética, o en todo caso están muy cerca de la línea divisoria entre lo que es y no es ético. Para algunas personas, el hecho de que un país rico y poderoso incumpla su palabra es simplemente cuestión de real politik: ¿acaso qué represalias podrían tomarse? Hay quienes irían más lejos aún, afirmando que si los funcionarios públicos se abstienen de hacerlo, estarían faltando a las responsabilidades que tienen ante sus ciudadanos, que incluye el procurarles el máximo nivel de bienestar. Si para lograrlo es menester mentir, engañar, robar, pues que así sea. Nuevamente puede invocarse la argumentación contraria a este comportamiento, inclusive a la luz de los criterios prácticos. 
En el mundo actual, también los países, por más poderosos que sean, necesitan la cooperación de otros, y si adquieren la fama de maltratar a terceros, de ser deshonestos y de incumplir su palabra, les será más difícil conseguir dicha cooperación. La falta de confianza tiene consecuencias aún más importantes en el ámbito internacional que en el económico, puesto que en éste existen mecanismos legales de ejecución que pueden substituir parcialmente la confianza. Sin embargo, no es así, en las relaciones internacionales.

En las secciones siguientes, quisiera pasar revista a varios temas surgidos recientemente a nivel de la política económica internacional vista a través del lente de la ética práctica. Cada uno de ellos puede ser abordado igualmente desde otras ópticas, y no pretendo tratarlos en forma completa. Pienso, sin embargo, que el enfoque a partir de una perspectiva ética brinda nuevas dimensiones de comprensión -inclusive para entender mejor el por qué de los visos morales que rodean ahora estos temas.

\subsection{Condonación de la deuda}

La condonación de la deuda se ha convertido en un tema de intenso debate público. Parece haber algo peculiar en la situación en la que países muy pobres transfieren dinero a los más ricos año tras año. Muchos países se ven obligados a desembolsar una fracción enorme de sus ingresos por concepto de exportaciones para pagar el servicio de su deuda, con lo cual es muy poco lo que queda para invertirlo en mejorar la situación de los pobres. El sobre-endeudamiento les impide crecer y reducir la pobreza. Resultan muy sombrías las perspectivas para estos países si no se les exime del pago de la deuda.

No quisiera referirme aquí a los aspectos económicos, sino a los temas y dilemas morales. Son especialmente cuatro, y no se les ha prestado suficiente atención. El primero es el relativo a la equidad entre países en desarrollo. De cualquier manera, la cantidad de recursos transferidos de los ricos a los pobres será limitada. La pregunta es ¿quién recibirá dichos fondos? Los fondos empleados para la condonación de la deuda podrían haber sido utilizados para ayudar a otros países necesitados, especialmente aquellos que son igualmente pobres pero que ya habrían pagado su deuda. ¿Es justo que los que han cumplido con su parte del contrato de préstamo se encuentren en una situación menos buena, o que no se encuentren fundamentalmente mejor, que aquellos que no cumplieron?

El segundo argumento gira alrededor de la responsabilidad moral de los prestamistas. 
Recordemos los préstamos otorgados a Mobutu en sus días de gloria. Los prestamistas conocían la corrupción de su régimen. Sabían que el dinero no llegaría a los habitantes del país. En el mejor de los casos, se trataba lisa y llanamente de préstamos de Guerra Fría; en el peor de los casos, se trataba de prestar para asegurar a las compañías occidentales la posibilidad de seguir explotando la riqueza de recursos naturales ¿Por qué razón la gente del Congo - que no tenía posibilidad de intervenir en la elección de Mobutu como su líder- debería devolver un dinero que fue entregado a Mobutu y dilapidado por él ¿Acaso no recae la responsabilidad moral en los prestamistas? (a esta clase de deudas suele denominárselas como "ociosas", y muchos críticos de las políticas de préstamos sugieren que el deudor no tiene la obligación moral de reembolsar la deuda, mientras que consideran que el acreedor sí tiene la responsabilidad moral de perdonarla).

Este caso parece bien sencillo, y resulta imposible obviar la responsabilidad moral de los prestamistas. Sin embargo, hay otras situaciones que podrían lucir un poco más complejas. Tomemos el ejemplo del préstamo otorgado por el FMI a Rusia en 1998. Allí había un gobierno electo, si bien se conocía con bastante certeza que había corrupción. Resultaba perfectamente evidente en ese momento que el tipo de cambio en Rusia estaba sobrevaluado, lo cual estaba teniendo efectos adversos en su economía; el FMI impuso políticas tendientes a la contracción (como parte de los condicionamientos exigidos para brindar la asistencia), causando una profunda caída en la economía que llevó a un marcado aumento de la pobreza (del $2 \%$ bajo el régimen anterior a casi $50 \%$ para 1998); asimismo, las políticas de privatización y de libre flujo de salida de capital, igualmente promovidas por el Fondo, condujeron a la acumulación de gran riqueza por unos pocos oligarcas.

¿Debería el FMI haber prestado miles de millones de dólares al país, con el claro conocimiento de la alta probabilidad de que dichos fondos simplemente le permitirían a unos pocos oligarcas sacar más dinero del país, que el mismo se vería agobiado por un mayor endeudamiento, que los pobres contribuyentes se verían obligados, en última instancia, a reembolsar el préstamo, y que, de cualquier manera, era poco probable que facilitaría un renovado crecimiento ( $y$ de hecho, al mantener el tipo de cambio en un nivel sobrevaluado, afectó adversamente el crecimiento)? Y si el FMI prestó dinero al país, dinero que fue luego utilizado por los oligarcas para sacar una mayor parte de su fortuna del país en condiciones más favorables, y si las políticas económicas fracasaron, ¿cuál es la obligación moral de los ciudadanos de reembolsar la deuda, o la del Fondo en el sentido de perdonarla? ¿Cuál es la responsabilidad moral que recae en el Fondo por su asesoría mal orientada, por su complicidad al suministrar los fondos en una situación con tal alta probabilidad de uso indebido de los mismos? 
El tercer aspecto es el relativo a la naturaleza del contrato de la deuda, y de la asesoría brindada a los países. En los mercados de capital que funcionan adecuadamente, el riesgo asociado a cualquier contrato se divide entre las partes de tal forma que a la que tiene la mayor capacidad para asumir dicho riesgo se le adjudica la mayor proporción del mismo. Pero los mercados de capital no funcionan tan bien en la práctica como en teoría. Los países en desarrollo son los que llevan el mayor peso de los riesgos asociados a las fluctuaciones de los tipos de cambio y de la tasas de interés, y son precisamente las marcadas variaciones de las mismas las que han conducido a muchos países a la difícil situación en la que se encuentran en la actualidad. Las instituciones financieras internacionales, naturalmente, tienen la oportunidad -yo diría que la obligación- de diseñar contratos que reflejen una distribución apropiada de la carga del riesgo, pero no lo han hecho. También han incurrido en omisiones, en numerosos casos, al no señalar a los países asesorados los riesgos asociados a las políticas de empréstitos que les recomiendan. Por ejemplo, antes de la crisis de Rusia en 1998, el FMI le aconsejó obtener préstamos en dólares, en función, aparentemente, de una más baja tasa de interés.

Resulta sin embargo, que es justamente el FMI la institución con la más firme creencia en mercados que tengan un funcionamiento adecuado $\mathrm{y}$, por lo tanto, debería haber señalado igualmente que en esas condiciones, las diferencias en tasas de interés (entre dólares y rublos) reflejaban el riesgo de fluctuaciones en el tipo de cambio y, por ende, si Rusia se endeudaba más en dólares, las consecuencias de una posible devaluación (que lucía altamente probable en ese momento) serían muy severas. El peso moral que se inclina hacia la condonación de la deuda parece aún mayor debido al deficiente diseño de estos contratos así como a la asesoría incompleta, y en algunos casos, equivocada.

El cuarto elemento está vinculado al tema de los conflictos de interés que señalé anteriormente. Una de las funciones de los cuantiosos préstamos de rescate ha sido la de suministrar fondos que permitan el reembolso a los bancos de Occidente. Se plantean potenciales conflictos de interés (a nivel individual $\underline{7}$ y organizativo $\underline{8}$, puesto que gran parte de los beneficios de estos préstamos son para los bancos y otros intereses financieros de Occidente, mientras los costos deben ser asumidos por los trabajadores y otros ciudadanos que se quedan en el país. Una asesoría y prácticas de préstamos éticas requerirían en señalar esta realidad. Cuando no ha habido una clara divulgación de esta información, ¿cuál es la obligación moral del prestatario de pagar? ¿cuál la del prestamista de perdonar?

Los aspectos éticos asociados al reembolso y métodos de cobranza de las deudas son de 
larga data y complejos. A través del tiempo, claramente se ha dado un cambio en los criterios éticos. Durante el siglo diecinueve, en Gran Bretaña, había prisiones para deudores. La mayoría de las personas consideraría en la actualidad que este tratamiento es un castigo cruel, no ético, a pesar de que posiblemente es un medio muy convincente para incentivar el pago de la deuda. De la misma forma, el trabajo forzado, ocasionalmente empleado como mecanismo de cobranza de deuda en los países en desarrollo, además de ser ilegal en la mayoría de ellos es igualmente falto de ética, y prácticamente equiparable a una situación de esclavitud.

La invasión de un país por otro para exigir cumplimiento de un contrato de endeudamiento también se consideraría como algo falto de ética en la actualidad, si bien durante el siglo diecinueve ocurrió en varias oportunidades. A nivel individual, tasas de interés usureras así como la imposición de otras "condiciones" asociadas a la usura también se considera como falto de ética. Los extensos condicionamientos impuestos por el FMI, vinculados a los préstamos otorgados a países que se encuentran desesperadamente necesitados de fondos plantean interrogantes similares, a saber: ¿cuándo constituyen dichos condicionamientos un abuso de poder, y resultan por lo tanto no éticos? Me referiré brevemente a estos interrogantes $m$ ás adelante.

\subsection{Otorgamiento de préstamos}

En el momento de analizar la conveniencia de otorgar un préstamo a un país, es suficiente plantear una pregunta muy sencilla: ¿se encontrará el país en su conjunto en una situación más favorable con el préstamo de lo que estaría si no lo recibe, habida cuenta de que aumentará su situación de endeudamiento? Si existe una probabilidad razonable de un mayor deterioro de la situación del país, resulta cuestionable el aspecto moral de otorgarlo (de hecho el económico también). Los incentivos de la institución prestamista y de sus funcionarios, y los del gobierno prestatario pueden diferir marcadamente de estos dictámenes morales. Es probable que el gobierno piense que el dinero le brinda una oportunidad para sobrevivir, y en todo caso, si no funciona, será problema de otro. Retomando el caso del préstamo del FMI a Rusia, uno de los argumentos para concederlo era que aumentaría la supervivencia de Yeltsin, considerado como amigo del FMI y de los Estados Unidos; más específicamente, la caída de Yeltsin sería vista como un fracaso de la política del FMI y del Departamento del Tesoro de los EEUU.

Los incentivos de éstos últimos no necesariamente coincidían, en este contexto, con los intereses de Rusia, si bien cabe decir que el FMI y el Tesoro estadounidense podrían haber 
creído que su capacidad para evaluar criterios políticos acertados era mayor que la de los votantes de Rusia, (en la literatura sobre el tema se ha señalado la discrepancia existente entre los incentivos para los individuos y para las organizaciones. Para citar un ejemplo, la teoría de los compromisos en escalada señala que el costo de abandonar una estrategia que se ha promovido puede ser mayor para un individuo que para la organización). Otro ejemplo, es el de la reciente debacle de Argentina: en el momento del préstamo de Agosto de 2001, incluso los integrantes del Directorio del FMI eran escépticos en cuanto al posible beneficio que podría aportar el dinero al país. Además de elevar el nivel de endeudamiento, era remota la probabilidad de que le permitiera sobrevivir más que unos pocos meses sin entrar en una situación de devaluación o de incumplimiento de pago. Sin embargo, cabe suponer que respondía a los intereses del Director General Adjunto, quien estaba a punto de dejar el cargo.

El negar el préstamo habría precipitado una crisis en ese mismo instante, poniendo al descubierto el ruidoso fracaso de las políticas promovidas por él. Una mínima posibilidad de éxito del programa reivindicaría sus políticas. Si fallaba, él no tendría que asumir las consecuencias: serían los habitantes del país los que pagarían el costo del aumento de la deuda. El nivel de cinismo de los integrantes del Directorio era tal para ese momento, que se referían los $\$ 8.000$ millones como un regalo de despedida para el Director Gerente Adjunto a punto de partir, puesto que era probable que el dinero mantuviese las cosas "parchadas" hasta su salida del Fondo, con lo cual le evitaría la vergonzosa situación en lo inmediato, aunque no por mucho tiempo.

En resumidas cuentas, existen razones para creer que los intereses del gobierno beneficiario del préstamo y de las instituciones otorgantes (FMI) pueden ser marcadamente diferentes de las de los habitantes del país. El FMI y sus funcionarios quisieran convencer a los demás de que son diferentes de otras instituciones públicas y privadas; si bien reconocen el papel que juegan los incentivos distorsionados y enfocados hacia la rentabilidad, especialmente en las instituciones gubernamentales, ellos se consideran inmunes a dichas distorsiones. Es poco lo que se conoce en materia de teoría o pruebas que permitan sustentar esta visión. Cuando se ha prestado dinero a un país por razones diferentes a las de promover su desarrollo (por ejemplo conservar la amistad del gobierno en ejercicio durante la Guerra Fría), el argumento ético a favor del perdón de la deuda se fortalece, a la vez que se reduce la obligación moral de reembolsarla.

Hasta el momento he recalcado el hecho de que en numerosas situaciones se han otorgado préstamos en circunstancias en las que podría argumentarse que no deberían haberse concedido, por plantear aspectos éticos vinculados a su reembolso. También se 
presentan situaciones similares, circunstancias en las que el argumento podría ser a favor de otorgar los préstamos, pero en las que se retiene el dinero o se imponen condiciones en las cuales se aprovecha de la situación de debilidad del prestatario. El caso de Ecuador podría ilustrarlo. Suministrar dinero en un momento crítico a un país que se encuentra ante una crisis de liquidez debido a una serie de situaciones adversas, entre ellas la baja de los precios del petróleo, una posición agrícola debilitada debido a El Niño y a una enfermedad que afectó a los camarones, una de sus principales cosechas de exportación (gracias a las reservas de petróleo, la posición financiera a largo plazo del país era más positiva) hubiera sido totalmente lógico desde el punto de vista económico, y era también la conducta más ética. Podría haber posibilitado la supervivencia de un gobierno elegido democráticamente.

Sin embargo, al FMI se le habían venido dirigiendo marcadas críticas por los rescates de gran magnitud, y había una presión que favorecía la aplicación de una política de cobertura interna - la participación del sector privado-. Era demasiado arriesgado ensayar esta nueva estrategia con países ricos y poderosos como Brazil y Rusia, por lo cual se eligieron débiles como Rumania y Ecuador para el experimento, con consecuencias adversas para ambos.

\subsection{Política comercial de los países desarrollados}

Los disturbios en Seattle permitieron percibir la magnitud de la insatisfacción por la forma en que se han venido conduciendo las negociaciones internacionales en materia de comercio, modalidad que probablemente se mantenga. Los puntos de la agenda habían sido determinados por los países ricos y poderosos para que reflejasen sus intereses particulares. Y los resultados reflejaban su poderío económico. En efecto, según revelan cálculos realizados, la situación de África del Sub-Sahara después de la ronda de negociaciones comerciales de Uruguay (culminada en 1994) se había deteriorado en comparación con la anterior a dicha ronda. Los Estados Unidos presionaron a favor de la liberalización de los servicios financieros y de la tecnología de la información, así como por una cobertura más amplia de protección a la propiedad intelectual. Se interesaban menos por otros servicios tales como el sector marina y construcción, o incluso los efectos potencialmente adversos de una aplicación excesivamente rígida de la propiedad intelectual en aquellos habitantes de los países en desarrollo, cuyas vidas dependen de la disponibilidad de drogas poco costosas.

En las negociaciones de comercio con Corea (y con otros países), abogaron a favor de una rápida liberalización de los mercados financieros y de capital, a pesar de tener pleno 


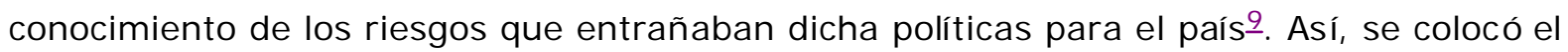
bienestar de la comunidad financiera de los Estados Unidos por encima del de los trabajadores de los países en desarrollo. Durante el intento por parte de Estados Unidos para demorar las negociaciones tendientes al ingreso de China a la OMC, llegaron incluso a afirmar que China no es un país en desarrollo, si bien el Banco Mundial (así como los demás organismos internacionales) la clasifican en esa categoría.

En cierta forma es natural que un país promueva sus propios intereses. Pero, como lo planteaba con anterioridad, ¿en qué punto se convierte esta actitud, (que a menudo más que los intereses de un país promueve realmente los de un grupo de intereses particulares dentro del mismo), a expensas de los pobres, en un asunto que atañe a lo moral?

Hay un aspecto en estos debates que me preocupa especialmente en mi condición de asesor económico: cuando los argumentos esgrimidos a favor de la posición de los Estados Unidos rayan en la hipocresía y la deshonestidad. Por ejemplo, mientras los EEUU (y el FMI) dictaban cátedra a los países en desarrollo acerca de los males de los subsidios y las virtudes del libre comercio, los gobiernos occidentales mantenían enormes subsidios y barreras comerciales en la agricultura, que es un área de ventaja comparativa para muchos países en desarrollo. Los Estados Unidos y Europa acusaron a otros de "dumping" -y bajo esa estratagema, erigían nuevas barreras comerciales- a pesar de que son pocos los economistas que calificarían de "dumping" lo que hacían esos países ¿No hubiese sido mejor actuar de manera más honesta y directa, admitiendo que las presiones políticas internas nos obligaban a adoptar políticas difíciles de justificar?

\subsection{Elementos externos globales: el entorno global}

Enseñamos a nuestros hijos que no se debe botar basura. Este es un ejemplo de un elemento externo, de una acción ejercida por un individuo que afecta a terceros, y cuyos costos no asumen quienes la cometen. Las políticas gubernamentales están diseñadas para limitar el alcance de los elementos externos, pero son imperfectos: los mecanismos de control social -un sentido de lo correcto y de lo equivocado, lo que está bien y lo que está mal. Suposiciones previas de lo ético- son más efectivos. Las acciones de las personas en un país también tienen efectos en otros, y en virtud de la ausencia o debilidades del derecho internacional en esta materia, resulta necesario depender de normas éticas. Por ejemplo, está mal que un país ubique un vertedero de basura en su frontera de tal manera que por la dirección del viento se disemine la contaminación hacia el aire del país vecino. 
El reconocimiento de que todos compartimos el mismo planeta, de que sus recursos son limitados y que políticas erróneas pueden malgastarlos y dejar a las generaciones futuras en situación de riesgo ha sido muy lento y gradual. Hoy por hoy existe una aceptación general de los peligros del calentamiento global, y las Convenciones de Río y de Kyoto dan fe de esta preocupación. Hay sin embargo un aspecto profundamente preocupante en el marco de dichas Convenciones, basado en el criterio de reducciones de los actuales niveles de emisiones. Resulta difícil detectar un principio de equidad subyacente: aparentemente, los países desarrollados tienen el derecho de contaminar más que los de menor desarrollo (sobre una base per cápita) por el simple hecho de que han contaminado más en el pasado ¿Hay acaso alguna justificación moral para esta política? Podría pensarse en marcos alternativos, en los que intervengan, por ejemplo, acuerdos para emprender políticas compartidas (como impuestos universales a la emisión de carbono) que parecerían tener un fundamento ético más sólido.

La posición ética de los Estados Unidos, el mayor emisor de gases de invernadero, tanto sobre una base per cápita como en términos absolutos, resulta aún más difícil de comprender. Afirma que no tiene que hacer nada porque los países en desarrollo no se han comprometido a emprender ninguna acción, si bien la acumulación de gases de invernadero se debe mayormente a los países industrializados, y a pesar de la consideración que aunque se comprometiesen a no permitir emisiones de niveles superiores a las de los Estados Unidos sobre una base per cápita, pasarían décadas antes de que dicha limitación sea obligante.

\subsection{Equidad inter-generaciones, ambiente, política de población}

Las dimensiones morales, además del trato a quienes viven en la época actual, abarcan igualmente a las futuras generaciones. Al agotar los recursos naturales, sin compensar con otros patrimonios físicos, dejamos más empobrecidas a las futuras generaciones. Esta viola el principio de la equidad inter-generaciones o justicia social. Muchos países en desarrollo están explotando actualmente sus limitados recursos naturales sin tomar las precauciones adecuadas para el futuro. Existen marcos de referencia contables (contabilidad "verde" o "ecológica") diseñados para promover una mayor equidad intergeneraciones. Sería importante motivar a los gobiernos para que utilicen dichos sistemas contables, y también para que reserven fondos, o inviertan en capital físico y humano.

Posiblemente el determinante más importante de la degradación ambiental (inclusive el vinculado a las emisiones de carbono) es el del crecimiento demográfico, el cual impone una amplia gama de elementos externos, como lo reconociera Edgeworth (1988) hace 
mucho tiempo. Los países con elevadas tasas de crecimiento demográfico tienen dificultades para incrementar los niveles de ingreso (per ápita), lo cual conlleva una mayor probabilidad de tener tasas de pobreza más elevadas. En efecto, durante la última década del siglo diecinueve, la carrera entre el mejoramiento de las condiciones de vida y el crecimiento demográfico la ganó este último: si bien disminuyó el porcentaje de la población pobre, el número absoluto de personas que viven en condiciones de pobreza absoluta aumentó. Las familias numerosas, además de las dificultades para alimentar a sus hijos (y la desnutrición infantil deja secuelas de por vida), no podían costear su educación, con lo cual condenaban a la siguiente generación a la pobreza y al sufrimiento. Disponemos en la actualidad de los medios para el control de la población. Diría que los gobiernos tienen una obligación moral de adoptar políticas en este sentido.

\subsection{Crisis}

Anteriormente hice alusión a los dilemas morales que a mi entender se vislumbran en el marco de la crisis financiera global. No quisiera referirme al problema de asignar "culpas" ni al fracasado manejo de la crisis, sino centrarme en el aspecto de la ética en el contexto de las asesorías y ayudas internacionales. No cabe duda que las políticas adoptadas internamente por los países contribuyeron a la crisis: la corrupción y regulaciones financieras inadecuadas también tuvieron su papel. Pero no se trata de eso, sino de cómo intervenir en la crisis para minimizar el daño, especialmente para los pobres, y a la vez colocar las bases para corregir los problemas subyacentes. EI FMI no lo logróñ.

Los intereses de los acreedores extranjeros fueron antepuestos a las preocupaciones por los trabajadores y por las pequeñas empresas, sectores que no tuvieron arte ni parte en la crisis (no fueron sus empréstitos los que la desencadenaron) pero sí se encontraron bajo los terribles efectos de la intervención, desde un desempleo desbocado hasta el derrumbe de los salarios. Se eliminaron los subsidios a los alimentos para los pobres justo en el momento en que más los necesitaban. La alteración del clima político y social -y los numerosos muertos- eran predecibles y, de hecho, fueron previstos con anterioridad ¿Cuál es la responsabilidad moral de quienes promovieron políticas cuyas consecuencias han sido tan desastrosas? Especialmente en vista de que su asesoría previa, que alentaba e incluso exigía una rápida liberalización del mercado de capitales, fue posiblemente el factor individual más importante que contribuy ó a la situación de crisis? Todavía, cuando las políticas promovidas no condujeron a los resultados previstos, el FMI y el Departamento del Tesoro de Estados Unidos culparon al país, con lo cual contribuyeron más aún a ahuyentar a los inversionistas. 
Como lo señaló Jeffrey Sachs, era como lanzar una alerta de incendio en un teatro abarrotado de público. Actuar así, además de ser mala política económica, implica abusar de la confianza puesta en las instituciones. Puede afirmarse que se trata fundamentalmente de un acto inmoral, tanto como puede serlo dar la voz de alarma en una sala de teatro llena, por saber que el hacerlo puede generar una alteración del orden y muertes innecesarias. Estos son interrogantes que brillan por su ausencia en las instituciones internacionales o en el seno de los gobiernos que imponen las políticas que imperan en ellas. Sin embargo, corresponden a las preguntas que con insistencia creciente se hacen los ciudadanos corrientes tanto en el Tercer Mundo como en los países industrializados de mayor desarrollo.

Los gobiernos en ejercicio que aprobaron dichas políticas, también llevan su parte de responsabilidad, pero a menudo se sentían sin opciones, -lo cual, de hecho, es lo que se les dijo- los asesores externos sí tenían otras opciones para brindar consejos diferentes. De hecho, había controversia acerca de cuán apropiadas eran las diversas políticas. Así, no se trata de evaluar si los propios países afectados y sus gobiernos tienen parte de la responsabilidad. Sin duda la tienen. Mi preocupación aquí está vinculada a la culpabilidad moral del FMI, que todavía está por ser reconocida.

Quisiera referirme brevemente a varias dimensiones éticas de la conducta del FMI. Primero, los consultores no actuaron de manera honesta en la forma en que transmitieron la información relativa a los riesgos e incertidumbres y en la que presentaron el rango de opciones. Segundo, está el tema del efecto de compensación entre las devaluaciones y los incrementos de las tasas de interés, así como los aspectos morales vinculados a la responsabilidad. El FMI sostenía que el aumento de las tasas de interés era la única manera de prevenir un mayor descenso del tipo de cambio. En realidad, las políticas de tasas de interés elevadas no fueron efectivas para detener la caída del tipo de cambio; por el contrario, es probable que hayan contribuido a la misma, por ser un elemento conducente a una mayor profundización de la recesión/depresión, con lo cual se indujo la huida de capital, en vez de atraerlo.

Pero no debe confundirse este error de criterio económico $\underline{11}$ con el aspecto moral más profundo. En varios de los países, la raíz del problema estaba en el exceso de empréstitos externos. Quienes estaban obteniendo préstamos tenían la posibilidad -y la mayoría de los economistas diría que deberían haberlo hecho así- de obtener una "cobertura" (un seguro efectivo) para protegerse de fluctuaciones en el tipo de cambio. Ningún gobierno garantiza su tipo de cambio, y no existen tipos de cambio fijos. Los tipos de cambio fluctúan, la única diferencia entre reg ímenes está en la frecuencia, magnitud y, más generalmente, en 
las reglas que rigen dichas fluctuaciones. El mercado, de hecho, estaba indicando a los prestatarios que había un riesgo de devaluación (en situación de equilibrio, la diferencia entre las tasas de interés internas y externas es igual a la tasa de cambio prevista en el tipo de cambio, más una prima por riesgo).

La actitud del FMI, una vez que se presentó la crisis, fue la de solventar a quienes habían "apostado" por la posibilidad de que no cambiaría el tipo de cambio (que no habían adquirido cobertura) a expensas de quienes no tenían arte ni parte en la situación creada. En cierta forma, quienes ocasionaron la crisis por obtener un exceso de empréstitos a corto plazo en el extranjero salieron mejor librados (por lo menos en parte), a expensas de quienes simplemente estaban tomando empréstitos corrientes en el marco de la conducción de su negocio. Visto en este contexto, este rescate plantea aspectos morales inquietantes, además de los temas más extensos de riesgo moral que han sido debatidos ampliamente (el patrón de rescates inspirados en el modelo del FMI reduce el incentivo que pueden tener los prestatarios que se endeudan en el extranjero para obtener cobertura).

\section{Estrategias de crecimiento y reducción de la pobreza}

En la actualidad, se reconoce a todo nivel la importancia de reducir la pobreza. EI FMI cambió la denominación de su programa para los países en desarrollo para incorporar los conceptos de crecimiento y lucha contra la pobreza. La teoría económica fundada en el criterio del "goteo", en función del cual se justifican los programas que enriquecen más aún a los ricos con el argumento de que los beneficios terminarán por "gotear" hacia los pobres, ya no está en boga. Pero dejando la retórica de lado, hay un activo debate relativo a las políticas económicas. La posición del Tesoro de los Estados Unidos y del FMI puede caracterizarse como de "goteo plus": el crecimiento es necesario y casi suficiente para reducir la pobreza; por consiguiente, la mejor estrategia para ayudar a los pobres es la de adoptar reformas que optimicen el crecimiento - la misma agenda noe-liberal-, con su énfasis en la privatización y la liberalización, que había prevalecido durante las dos décadas recientes, a la cual se le agregan la educación y la salud. Las modificaciones a la fórmula tradicional representan pasos importantes en la dirección correcta.

Sin embargo, el fundamento subyacente adolece de varias fallas. Es un hecho concreto que los países de mayor éxito en su desarrollo durante el medio siglo reciente -a saber los del Este de Asia- no han adoptado las políticas del consenso de Washington. Por otra parte, muchos de los países que sí han seguido estas políticas no han tenido un desarrollo especialmente bueno ( $s$ i bien el "doctor" aduce que no se siguieron los lineamientos 
prescritos con suficiente precisión). Actuar con honestidad, hubiese implicado compartir la información disponible con total transparencia, a saber que la evidencia que justifica las políticas resultantes del consenso de Washington es, en el mejor de los casos, ambigua, y el omitir este conocimiento plantea situaciones vinculadas a lo moral $\underline{12}$.

Tal vez de mayor importancia aún, la preocupación por los pobres debería haber llevado a prestar mayor atención a las consecuencias de los países que mejor han logrado reducir la pobreza han hecho mucho más que depender del efecto de "goteo". Ilustraré esto con algunos ejemplos:

- Los países más exitosos en el mejoramiento de la condición de los pobres han tenido una estrategia explícitamente orientada al crecimiento de este sector, que va más allá de la simple afirmación de la importancia de los sectores educación y salud.

- A menos que se le den activos a los pobres -como mediante reformas agrarias- es probable que sigan atrapados en la pobreza. Naturalmente, la reforma agraria podría afectar algunos intereses particulares. Resulta extraño que mientras quienes en este momento poseen gran riqueza en muchos de los países pobres la adquirieron en formas poco legítima (por ejemplo mediante el ejercicio de la fuerza bruta por parte de amos coloniales), consideren que quitarles parte de la misma constituye una derogación de valores fundamentales de los "derechos de propiedad".

- La disparidad entre la propiedad de recursos (como la tierra) y la fuerza laboral da lugar a instituciones como la de los aparceros, conducentes a incentivos atenuados y producción reducida. En el marco de un sistema de aparceros, los agricultores arrendatarios, en efecto, se encuentran sometidos a tasas impositivas de $50 \%$ o más. Si bien el FMI se ha pronunciado firmemente contrario a las tasas de tributación elevadas, y ha señalado cómo afectan negativamente el esfuerzo, no ha tenido la misma vehemencia para expresarse a favor de la reforma agraria, que reduce estos problemas vinculados a las instituciones, a la vez que aumenta la eficiencia económica y la equidad.

- Algunas de las reformas económicas promovidas por el FMI y por el Tesoro de los Estados Unidos tienen dudosos efectos en el crecimiento, pero sí aumentan la vulnerabilidad de los países ante los shocks (el ejemplo más obvio es el de la liberalización de los mercados de capital). Son los pobres quienes inevitablemente llevan la peor parte de los descalabros, a pesar de todo lo que se habla acerca de la importancia de crear redes de seguridad. La honestidad requeriría observar que aún en los países más desarrollados, son inadecuadas dichas redes para los agricultores y las personas que trabajan por su cuenta. 
- Pero incluso los beneficios de la liberalización del comercio quedan en entredicho cada vez mayor, a menos de que esté complementada por medidas que permitan la creación de nuevas empresas y empleos; sin embargo, los paquetes del FMI a menudo acompañaron las medidas de liberalización comercial con elevadas tasas de interés, que convierten la creación de empleo en algo virtualmente imposible, aún en el marco de una economía de mercado de buen funcionamiento. La cosa es muy sencilla: la liberalización del comercio a menudo conduce a una pérdida de empleo. La ideología del libre mercado asegura que esto permite que los recursos fluyan de usos menos eficientes hacia los de mayor eficiencia. Ojalá fuese así. El problema radica en que en muchos países de menor desarrollo, los mercados no funcionan bien (eso es parte del hecho de ser de menor nivel de desarrollo). Las tasas de desempleo son elevadas. La creación de empleo resulta difícil. El desplazamiento de la mano de obra de trabajos de baja productividad hacia el desempleo reduce el PIB de un país e incrementa la pobreza. Con frecuencia, sin embargo, eso es precisamente el efecto que tienen los paquetes del FMI en los que se combina la liberalización con las altas tasas de interés.

- Aún en el caso de que el país tenga éxito en la creación de nuevos empleos, es posible que afecte de manera adversa a los pobres, puesto que una mayor apertura puede conducir a una sensibilidad acrecentada ante los "shocks" del mundo externo, que golpean mayormente a los pobres. La inseguridad constituye uno de los mayores problemas para los pobres, con lo cual las políticas que incrementan dicho sentimiento de inseguridad afectan aún más su situación.

- Con frecuencia, los programas de privatización han tenido efectos adversos, especialmente para los pobres. Así, los programas acelerados en esta dirección han conducido a la privatización de monopolios, sin supervisión reguladora. Dichos monopolios, si bien pueden haber resultado, o no, más eficientes en cuanto a producción, en algunas oportunidades han resultado ser más eficientes en la explotación de los clientes. La privatización ha demostrado ser un importante vehículo tanto para la corrupción como para la creciente desigualdad, faceta que salió a relucir claramente a través de las experiencias en Rusia. En efecto, uno de los incentivos para la rápida privatización que allí se dio consistió en que quienes recibieron activos del Estado a un valor inferior al del mercado seguidamente aportaron su contribución (no solamente financiera, sino también en el apoyo aún más valioso a nivel de la organización y cobertura de los medios) a favor de la reelección de Yeltsin. El silencio ante este trato corrupto de préstamos a cambio de participación accionaria fue muy elocuente: el fin justifica los medios.

- El FMI ha adoptado una definición especialmente estrecha (y peculiar) de lo que es buena política presupuestaria, en la cual la ayuda extranjera externa no se incluye o 
descuenta como una fuente de ingreso. La razón invocada para ello es la de que la ayuda externa es volátil, y por lo tanto no se puede contar con ella en forma permanente. El Banco Mundial analizó esta afirmación, y demostró que los ingresos tributarios son aún más volátiles. Por lo tanto, según la lógica del Fondo, los ingresos por recaudación tributaria tampoco deberían contabilizarse como ingresos, con lo cual ningún país está en posición de equilibrio presupuestario. Más pertinente para el aspecto en cuestión es que la respuesta apropiada ante flujos de ingreso volátiles es la de tener flexibilidad en el gasto. Los países construyen nuevas escuelas y centros médicos a medida que reciben el dinero. Cuando se detiene el flujo de la ayuda, igualmente paran las construcciones. A pesar de los extensos debates que he sostenido con la gente del Fondo, jamás escuché una justificación adecuada para su posición. Sin embargo, las consecuencias deben ser claras. Significa que un aumento en la asistencia externa no necesariamente se reflejará en un mayor número de escuelas o de clínicas, solamente se tratará de más dinero que entra a las reservas del país.

El aspecto económico de tasas políticas ha sido tema de debate desde hace mucho tiempo, tanto dentro del ámbito de la profesión como también en la sociedad civil. Mi intención al plantear estos conceptos no es la de retomar ese debate, sino de recalcar su dimensión moral. La posición presupuestaria del Fondo implica que se construyen menos escuelas y clínicas para perjuicio de los pobres. Esta política, así como las anteriormente descritas, incrementa los riesgos que deben afrontar los pobres. En algunos casos, tales como la liberalización del mercado de capitales, estas políticas parecen ser de cuestionable beneficio para el país en su conjunto, si bien es posible que beneficien a las comunidades financieras tanto nacionales como, más probablemente, a las del extranjero. Sin embargo, se han cometido pecados tanto de omisión como de acción: puede afirmarse que la reforma agraria habría incrementado tanto la eficiencia como la equidad.

En retrospectiva, pensando en las políticas coloniales, en los injustos tratados comerciales impuestos a Japón, en las Guerras del Opio, nos estremecemos ante su aparente falta de justificación moral. Al igual que nos inspiran ironía las descripciones del "Fardo del Hombre Blanco", especialmente a la luz del legado que dejó en África y en tantos otros lugares el mundo colonial. Ya no recurrimos el poderío militar para abrir mercados, pero los países industrializados avanzados sí hacen valer su poderío económico. Lo emplean para concertar acuerdos internacionales en los cuales una parte desproporcionada de beneficios son devengados por los países desarrollados, y, en algunos casos, los de menor desarrollo se encuentran en una situación aún peor que antes. 
En esta sección, he preguntado si las mismas objeciones que se le hacen al colonialismo se podrían de hecho aplicar igualmente a las políticas económicas impuestas a estos países. Inclusive cuando ayudan a los pobres, ¿existen otras opciones de políticas que podrían haberles sido aún más útiles, o que habrían implicado menores riesgos para ellos? Las instituciones internacionales que han promovido estas políticas, ¿han sido honestas en la descripción de sus riesgos?, ¿Han incurrido en actitudes deshonestas al exagerar la evidencia relativa a sus beneficios económicos? (sin duda las promesas de beneficios resultantes de la reforma económica en Rusia han excedido ampliamente al resultado obtenido. Las tasas de pobreza han aumentado, en un breve espacio de 10 a ños, del $2 \%$ a casi $50 \%$ ). Tal vez deberíamos preguntarnos si nuestros hijos verán las relaciones económicas de la actualidad con el mismo rechazo -el mismo sentimiento de indignación moral con el que nosotros evaluamos la experiencia colonial-. Lo vivido en Seattle y en Washington, así como extensas conversaciones con gente joven de todo el mundo hacen pensar que no tendremos que esperar mucho por esas reacciones: la juventud actual pone en tela de juicio la legitimidad moral de estas políticas. Sus defensores afirman que no hay alternativa: hay una receta única para el éxito. En esto se equivocan, y aún si existiese esa mejor receta única, los países que han logrado crecer y a la vez reducir la pobreza conferirían credibilidad al criterio de que no es la prescrita por las instituciones internacionales, que no presta la debida atención a un desarrollo democrático, equitativo y sostenible.

\section{Una perspectiva general}

La ética atañe a la relación que sostienen las personas entre sí, así como con la comunidad y con la sociedad en un sentido más amplio. Involucra las normas morales reconocidas como requisitos para la convivencia en el marco de comunidades que funcionan adecuadamente. Está mal asesinar, atracar o infligir otras formas de daño a terceros. En las sociedades modernas, sin embargo, es posible causar daño a otros de diversas maneras - así cuando un individuo arroja basura, está dañando el ambiente, y con ello lesiona el bienestar de aquellos para quienes es valioso preservarlo. Máximas muy sencillas como "trata a los demás como quisieras ser tratado", o "no hagas a otros lo que no quisieras que te hagan a ti", al igual que criterios básicos como los imperativos categóricos de Kant brindan lineamientos ampliamente aceptados; por supuesto, visto cuán complejo es el mundo, cabe suponer que la aplicación de los anteriores en determinadas circunstancias puede no ser tan evidente, e incluso, no estar exenta de ambigüedad. Señalamos anteriormente que, desde la perspectiva actual, la esclavitud nos parece una aberración, y el colonialismo -junto con la mentalidad colonial- lo vemos como 
una violación de normas éticas básicas. Pero, ¿es acaso la imposición de la voluntad de una persona -o de un país- a otro, por la fuerza del poderío económico, más aceptable que la imposición por la fuerza del poderío militar? Durante el siglo diecinueve, ambas cosas estaban a menudo entrelazadas, y se recurría al poderío militar para imponer obligaciones económicas.

En la actualidad, puede decirse que las cosas se hacen con un grado mayor de sutileza, pero ¿acaso son por ello más aceptables? En circunstancias de vida habituales, se consideraría que constituye una violación de las normas éticas el aprovecharse de una persona que se encuentre en una situación difícil transitoria; sin embargo, a nivel internacional, suele verse esto, sencillamente, como el estado natural de las cosas. ¿Debería considerarse que la imposición de condiciones a los países que requirieron apoyo financiero durante la última crisis global - condiciones no relacionadas con la crisis, o con el pago de la deuda- como una violación de normas éticas?, ¿Aún cuan sean (por lo menos desde la perspectiva de quien impone las condiciones) para beneficio de la otra parte?

Muchos preceptos éticos están vinculados a las acciones que socavan a la "comunidad". El proceso de desarrollo, por muy bien que se ejecute, suele socavar algunos valores tradicionales, algunos aspectos de la cultura tradicional. Pero si se realiza de una manera equivocada, puede tener efectos devastadores. La forma en que se condujo la transición del comunismo a una economía de mercado en Rusia ha sido desastrosa, desde cualquier óptica, con un vertiginoso aumento de la pobreza (como observamos, al punto de que cerca de la mitad de la población se encuentra en condiciones de pobreza), junto con una caída de la producción, mientras unos pocos han acumulado enorme riqueza. No resulta por ello sorprendente constatar la completa erosión del sentimiento de comunidad y de las normas básicas de comportamiento, igualada en magnitud por el aumento de la "actividad de las mafias".

Los economistas han empezado a referirse a estas ideas en términos del concepto de capital social. Una de las razones que explican la diferencia entre la transición exitosa de China y el fracaso de la realizada en Rusia consiste en la relativa preservación del capital social en aquella, y su destrucción en la última (Hussein, Stern y Stiglitz, 2000). Pero sabemos también que las políticas económicas tienen un papel crítico; así, es más probable que las transiciones acometidas a través de medios bolsheviques, o con el ritmo o falta de preocupación por construir consensos sociales que los caracterizan, conduzcan a una erosión de capital social. Igualmente, en el caso de Rusia, las privatizaciones aceleradas contribuyeron a erosionar el poco capital social que aún quedaba después del régimen comunista: con el resultado de que unos pocos individuos tomaron el control de 
los cuantiosos activos anteriormente en manos del Estado, mientras la libre movilidad de capitales prácticamente les invitaba a enviar al extranjero sus ganancias mal habidas, a la vez que el Estado Argumentaba no tener suficientes reservas ni siquiera para pagar las pensiones.

Hablamos a menudo del "contrato social", y si bien nunca se pone por escrito formalmente, no por ello es menos susceptible de incumplimiento, o en todo caso que se perciba de esta manera. La hiperinflación es objeto de amplias críticas porque socava dicho contrato social. Se ha considerado que lo ocurrido en Rusia constituye una violación del mismo. Mientras el FMI, en medio de la crisis financiera global, argumentaba que el no pagar a los acreedores constituía una violación de la santidad de los contratos, a pesar de que la quiebra es una institución central en el capitalismo, parecía prestar poca atención a la violación de un contrato aún más importante, el contrato social, y podría considerarse que las consecuencias desastrosas en Indonesia son, en parte, un reflejo de dicha violación contractual.

Si como consecuencia de la erosión del contrato social ocurre un debilitamiento de la cohesión social en formas conducentes a mayor violencia, mayor corrupción, más delito, ¿qué culpa recae en quienes han contribuido a este desmantelamiento del capital social?, ¿Hasta qué punto debe asignárseles la responsabilidad moral de las consecuencias, especialmente cuando las mismas son el predecible -y cuando no inevitable, por lo menos el muy probable- resultado de sus acciones? Estoy planteando aquí algunos temas fundamentales: afirmé anteriormente que las políticas económicas a menudo se adoptan sin la debida atención al efecto que tendrán en los pobres, en el sentimiento de seguridad.

Sugiero que esto constituye una violación de preceptos éticos básicos. Sin embargo, las políticas económicas se preocupan aún menos por su impacto en la comunidad, en las redes de seguridad social y en las relaciones tradicionales. "Mercados laborales flexibles" significa que los patronos pueden sentirse en libertad de despedir trabajadores tan pronto dejan de ser necesarios: no existe la obligación moral de brindarles apoyo para que logren superar épocas de dificultades. Cualquier política que socave el sentimiento de comunidad, las normas sociales, la cultura y el orgullo de un país puede ser vista, desde esta perspectiva, como una violación en principios éticos.

\section{Responsabilidad individual e institucional}

La tesis que he propuesto hasta el momento es la de que las políticas hacia los países en desarrollo y en el marco de los mismos pueden ser enfocadas desde una perspectiva ética, 
a saber cómo se conjugan con preceptos básicos de comportamiento moral; igual puede hacerse al analizar la conducta de quienes son llamados a brindar su asesoría a dichos países. En este contexto, hemos visto que muchas de las acciones emprendidas por los gobiernos y recomendadas por terceros, entre ellos el FMI, no salen bien libradas. Ha habido extensas -y podría afirmarse que han sido innecesariamente extensasconsecuencias adversas para los pobres. No me he referido aquí a la totalidad del costo que implicó el manejo de la crisis de Asia por el FMI, por dar un ejemplo. No solamente se trata del hecho de haber aumentado la pobreza, si no de que los recortes en gastos sociales y de salud en países como Tailandia, por ejemplo, exacerbaron el debilitamiento de la economía, condujeron a un aumento de los casos de SIDA y por la misma pobreza aumentó la prostitución infantil.

En la jurisprudencia estadounidense, en numerosos estados, existe el principio de la negligencia contribuyente. Todas las partes que han tenido un papel en los resultados adversos deben asumir su responsabilidad respectiva. Temas similares se plantean en el ámbito de la ética. Sin duda, son los gobiernos, quienes en última instancia, deciden la adopción de las políticas emprendidas. Pero a menudo han sido objeto de las presiones del FMI, y lo hicieron impulsados por el sentimiento de tener muy poco margen de maniobra.

En este caso no hace falta desmenuzar la atribución de la "culpa". Podemos decir sin ambages que el FMI y quienes apoyaron dichas políticas, especialmente el Departamento del Tesoro de los Estados Unidos, que las promovió con insistencia, tienen una considerable carga de culpabilidad moral por los resultados.

En relación con el Holocausto, el mundo también llegó a comprender que los espectadores que observan pasivos mientras otros cometen (lo que se consideran potencialmente) actos viles también tienen una determinada responsabilidad moral. Las instituciones de nuestra sociedad, que son los guardianes de nuestra moralidad, tienen una responsabilidad especial en el planteamiento de estos temas. Esto resulta de particular importancia a la luz de las fallas de que adolece nuestro sistema de gobernabilidad global, en el cual apenas se escuchan las voces de las personas y países pobres, aún en aquellos asuntos que afectan sus vidas y su subsistencia, y en los que sistemáticamente se hace caso omiso de los principios democráticos. Lo positivo es que en el mundo actual existe el reconocimiento creciente de la importancia de estos temas. Es por lo tanto el momento oportuno para que quienes tienen la autoridad moral para hacerlo eleven sus voces y se unan al coro de los interesados a quienes atañen las circunstancias. 


\section{Consideraciones finales}

El medio siglo pasado ha mostrado que cuando hay crecimiento, el desarrollo es posible, pero ciertamente no inevitable. Ha demostrado igualmente que es posible combinar el crecimiento con la reducción de la pobreza, pero no es nada fácil. Actualmente se realizan numerosos debates acerca de políticas que ofrezcan la mejor manera de lograr una reducción de la pobreza y el crecimiento. Mi preocupación en el presente ensayo no ha sido la de retomar ese debate - si bien no he podido evadir el tocar algunos de los temas más sujetos a controversia- sino la de sugerir que hay dimensiones de dicho debate que resulta útil abordar desde la óptica de las dimensiones morales, de preceptos relativos a valores como la honestidad, la justicia y la preocupación por los pobres. Habrá quienes puedan afirmar que este idioma es el del corazón y no el de la mente. Yo les diría que las decisiones en materia de políticas públicas necesariamente tienen que hablar el idioma tanto del corazón como de la mente, y que es importante reflexionar en profundidad y de manera consciente acerca de las dimensiones morales de nuestras decisiones económicas, y que se puede - de hecho se debe- combinar esta clase de análisis moral con un análisis desapasionado y objetivo de las consecuencias y riesgos asociados con las opciones de políticas.

De hecho, es la ausencia de esta exigencia moral la que, con excesiva frecuencia, ha permitido que la ideología se imponga, una ideología que deshonestamente afirma beneficios mayores y más seguros de lo que la evidencia permite deducir, una ideología que suprime discusiones democráticamente significativas de diversos cursos de acción, y que pasa por alto, o por lo menos no tiene suficientemente en cuenta, las consecuencias adversas para los pobres. Así, veo al nuevo humanismo como un complemento del razonamiento económico desapasionado, no como su antítesis, y veo en la posibilidad de combinarlos la mayor promesa para un futuro orden económico internacional basado en la justicia social.

\section{Notas}

* La RVG le agradece al Dr. Bernardo Kliksberg las gestiones para la publicación de este trabajo.

1. Gran parte de lo que deseo decir podría justificarse a la luz de principios más generales, como por ejemplo el imperativo categórico de Kant o el análisis Rawlsiano de justicia social. Este último puede resultar especialmente útil para abordar los temas de equidad debatidos más adelante: ¿qué clase de orden social y económico internacional se querría tener tras un velo de ignorancia, sin saber si se nacería en un país desarrollado o en uno en vía de desarrollo. Hacia el final del presente trabajo, trataré de enmarcar algunos de los preceptos éticos dentro de un contexto más 
amplio: el de las reglas y normas que facilitan las interacciones sociales cooperativas.

2. La honestidad es un precepto que puede ser tomado como un valor en sí, o como un modo de instrumentación de acciones emprendidas sobre el fundamento de una información distorsionada pueden conducir a resultados adversos. Cabe suponer que uno de los motivos para la falta de honestidad es el de inducir a terceros a emprender acciones que no realizarían si conociesen la verdad. Así, el no revelar plenamente los riesgos de la liberalización de los mercados de capital -y el afirmar que la misma permite obtener ganancias a pesar de que es poca la evidencia que así lo demuestrapuede inducir a los países a liberalizar sus mercados, cosa que no habrían si tuviesen información más precisa; aún en el caso en que el país decidiese de todas maneras liberalizar sus mercados de capital, la información distorsionada puede ser causa de que no despliegue la red de seguridad que hubiese dispuesto si hubiese estado plenamente consciente de los riesgos.

3. El caso más sonado en años recientes de una supuesta violación de esta norma ética ocurrió en Rusia, donde se acusó a dos de los asesores estadounidenses de utilizar sus contactos con personas ligadas al medio para obtener licencias de creación de fondos que favoreciesen a sus amigos personales.

4. Me percato de que se trata de una línea divisoria muy tenue. Afirmé antes que el economista debe, en efecto, diferenciar su papel en la definición de conjuntos de oportunidades de la tarea política de elegir entre los puntos de dicho conjunto. Sin embargo, la información facilitada acerca de los mismos - por ejemplo el impacto en los pobrespuede incidir en las políticas que se elige adoptar. Alguien que no comparta los valores, que no se preocupe por los pobres, podría invocar el argumento de que el suministrar dicha información no solamente es irrelevante, sino que además distorsiona el proceso político de la toma de decisiones.

5. Así, debemos ver la "contabilidad verde" no solamente desde el ángulo de ofrecer un buen marco de contabilidad sino como un asunto vinculado a lo moral.

6. Recientemente, la persona que estaba a la cabeza del FMI pasó directamente de ese cargo a la Vicepresidencia del Grupo Citibank.

7. En vista de que muchos responsables de otorgar los préstamos tienen y tendrán conexiones con las instituciones financieras a las que se rescata.

8. En virtud de que los Ministerios de Finanzas (el Tesoro de los EEUU) y bancos centrales, con estrechos nexos con la comunidad financiera en los países industrializados adelantados -los prestamistas- son los responsables de las decisiones de préstamo.

9. Esta política fue promovida por el Tesoro de los EEUU, si bien el Consejo de Asesores Económicos, además de advertir acerca de los riesgos resultantes de la política y de su dudoso beneficio para el país, esgrimió igualmente el 
argumento de que representaba pocos beneficios para los Estados Unidos como tal; de manera que la política ilustra un ejemplo más del peso de los intereses particulares.

10. El FMI ha aseverado que la rápida recuperación de varios de los países afectados por la crisis global comprueba que su medicina funciona. Una mirada más detenida al patrón de recuperación de los mismos no confirma esta conclusión, como lo afirmo en otro escrito. El país que con mayor asiduidad ha seguido las prescripciones del FMI, Tailandia, sigue teniendo un PIB inferior al nivel previo a la crisis, y casi un $40 \%$ de los préstamos no han logrado su cometido. Malasia se recuperó rápidamente, pero nunca tuvo un programa del FMI. Indonesia continúa en una situación de profunda recesión, que puede atribuirse en parte a los disturbios inspirados en las fracasadas políticas del FMI, así como también al hecho de que las mismas llevaron a un número masivo de quiebras de las cuales el país aún no se ha recuperado, así como también a la estrategia de reestructuración del sistema financiero, que condujo a corridas con el efecto de socavar todo el sistema de banca privada. La recuperación de Corea se debió en parte al hecho de que decidió hacer caso omiso de los principales puntos del FMI: si hubiese adoptado la estrategia sugerida de deshacerse del así llamado capital excedentario en la industria de los chips, no hubiese podido aprovechar el giro global en ese mercado que alimentó su recuperación. El crecimiento de Rusia y Brasil fue resultado de las devaluaciones, que las políticas del FMI no hicieron más que postergar.

11. Hubo otros errores de criterio económico: el FMI llegó a la conclusión (sin evaluación empírica exhaustiva) de que permitir el descenso del tipo de cambio sería más nocivo para la economía que permitir el incremento de las tasas de interés. De hecho, en varios países, es poco probable que esto fuera así. En Tailandia, por ejemplo, quienes habían obtenido empréstitos externos eran las empresas del sector inmobiliario (y quienes les habían concedido los préstamos), que ya se encontraban eliminadas debido al colapso de la burbuja de la propiedad en dicho sector y para quienes un mayor descenso en el tipo de cambio no habría tenido mayores consecuencias (si bien podría tener un efecto adverso en las cantidades que podrían obtener los acreedores extranjeros), y los exportadores, que obtendrían por concepto de ingresos una cantidad similar a la que perderían en sus balances. Tal vez la razón por la cual no emprendieron una evaluación empírica más minuciosa acerca de estos efectos se deba a que realmente no era esa su preocupación, puesto que estaban más centrados en el impacto que tendrían en la capacidad con la que los países podrían reembolsar los préstamos a sus acreedores. Pero este cambio de mandato, diferente al del propósito para el cual fue creada la institución -a saber contribuir a sostener los países ante situaciones potenciales de dificultades- y esta falta de claridad en cuanto al verdadero objetivo de la política (de ser así) resulta en ś profundamente preocupante y plantea cuestionamientos en lo moral.

12. Resulta interesante observar que en el Informe sobre el Desarrollo Mundial de 1996, “Del Plan al Mercado", sobre el tema de la transición, la más exitosa - a saber la de China- recibe parcos comentarios, y es relegada en gran parte a "casillas". ¿Será porque su éxito - inclusive en la reducción de la pobreza- fue logrado con medios tan contrarios a la ortodoxia prevaleciente? 


\section{Bibliografía Citada}

1. Edgeworth (1888), "Mathematical Theory of Banking" (Teoría Bancaria Matemática), En J ournal de la Sociedad Real de Estadística.

2. Hussein, Stern y Stiglitz (2000), "Chinese Reforms from a Comparative Perspective" (Las Reformas en China desde una Perspectiva Comparativa): Incentivos, Organización y Economía Pública: Trabajos en Honor de Sir James Mirrlees. Peter J. Hammond y Gareth D. Myles (eds.), Oxford University Press, pp. 243-277.

3. Stiglitz, Joseph (1997), "Velando por el Interés Nacional: Los Principios del Consejo de Asesores Económicos", En American Economic Review, No. 87 (2).pp. 109-113. 